\title{
Symbols and Themes in Sandplay Therapy for Korean-Chinese Adolescent from Broken Families in China
}

\author{
Yeo Reum Lee* Chun Yu Sun ${ }^{* *}$
}

\begin{abstract}
$<$ Abstract $>$
The purpose of this study was to find the themes and symbols expressed in sandplay therapy by Korean-Chinese adolescents from broken families in China. This study was conducted with Korean-Chinese residents of Yanbian Prefecture in northeastern China. The subjects of this study were adolescents in broken families who did not live with their mother, father, or both parents for various reasons. Sandplay therapy consisted of eight sessions over one month. The subjects underwent 45 minutes of therapy in each session. With the agreement of the subjects and their guardians, the sandplay therapy process was photographed. Meaningful contents were noted in the sand scenes and abstract research themes were narrowed down. As a result, the observed contents were materialized and the common themes found in adolescents were categorized. To ensure the validity of this study, triangulation and peer debriefing were applied. A case-by-case analysis procedure was adopted. It was found that there were four common themes expressed, namely a 'sense of distance', 'wounded', 'hope', and 'newness'. This study afforded insights into the psychological difficulties and characteristics of adolescents from broken families as well as providing them with an opportunity for understanding and healing themselves.
\end{abstract}

Keywords : Korean-Chinese adolescents, broken families, sandplay therapy, symbols and themes

* Play therapist, Areum Children and Adolescent Counseling Center(dufma91@naver.com)

** Adolescent psychology counselor, Yanji city, Jilin province, China(qks333@hanmail.net) 
Journal of Symbols \& Sandplay Therapy, Vol.8 No.1.

\section{I . Introduction}

Korean-Chinese are ethnic minorities in China, who are the descendants of those who emigrated from the Korean peninsula(Huang, 2013). Today, there are about 2 million Korean-Chinese living in China (Jeong, 2016). As of July 2015, more than $30 \%$ of the 1,801,401 foreigners residing in Korea were Korean-Chinese(Korea Immigration Service, 2015). In other words, $25 \%$ of the total Korean-Chinese population are living in Korea. This trend is attributable to the massive immigration of Korean-Chinese, who are fluent in both the Korean and Chinese languages immigrated, to major cities in China, South Korea, or other foreign countries in the wake of the reform and opening-up policy. As a result, an increasing number of children and adolescents in the Korean-Chinese community do not live with their mother, father or both. The case applies to over 30,000 Korean-Chinese children and adolescents in the Yanbian Korean Autonomous Prefecture alone, which accounts for a staggering 50\% of all children and adolescents in the area(Ri, 2014). Because Korean-Chinese families who live in Korea take up a major proportion of multi-culture families in the society, a range of studies and policies have taken place for the parents and their children. However, Korean-Chinese children and adolescents who live in China while their parents have gone overseas to work are still placed in a blind spot. Despite growing interest in these adolescents, as they have emerged as a social problem in the Korean-Chinese community, there is still a lack of practical support in reality.

Children of overseas immigrants are highly likely to experience a range of difficulties in the face of various demands from a different macro-environment(Cho \& Lee, 2005). Formation of an attachment through a close relationship with the primary caregiver immensely influences emotional, social and cognitive developments of a child. Failing to establish attachment at an appropriate stage in life can obstruct the individual from carrying out the necessary tasks posed in different growth and development stages. Consequentially, the individual may have trouble adapting to society even in adulthood(Heo, 2014).

Experiencing trauma from periodic parent-child separations and also from the absence of a primary caregiver during adolescence can be a cause of various psychological disturbances in adolescents, who are environmentally sensitive and have yet completed their physical, cognitive 
and personality developments. In other words, the aforementioned Korean-Chinese adolescents are exposed to an environment that renders them vulnerable to psychosocial problem. Other external factors that contribute to difficulties adolescents are facing include overemphasis on academic performances, increased divorce rate and the absence of child education at home(Heo, 2002). Korean-Chinese adolescents from broken families display a range of emotional and behavioral problems-some of which include being withdrawn, moody, timid, vulnerable to emotions, rebellious, impulsive, neurotic as well as difficult interpersonal relationships, poor academic performance and strange habits-because they did not have the chance to develop a normal relationship with their parents and the parents were unable to respond to emotional changes of their adolescent children.(Lim, 2013).

Adolescents are limited in their ability to express verbally their childhood experiences and emotions. Hence they need a medium or a tool that can help them express their inner aspect and thereby overcome inner psychological difficulties. Sandplay therapy allows clients to use sand, water and figures to symbolically express their inner world creatively and spontaneously within the space of a standard-sized sandtray. It is a self-healing method through which clients are able to heal themselves by recreating the images of their experienced world and their inner world into concrete forms(Kim, 2012). And when the therapist is able to attune to the symbolic meanings in sandpictures, the client-therapist relationship enables the client to reexperience the early mother-child unity, which is healing. Healing can occur even when the therapist does not verbally express what he or she has picked up from the client and the sandpictures(Jang, 2017). Because sandplay therapy is a nonverbal method, it may be the right therapy technique for Korean-Chinese adolescents who are at a stage in which they are not familiar with expressing their emotions, especially verbally. By enabling them to represent their experiences symbolically and projecting their inner contents on the figures, sandplay therapy can help them express their emotions.

By providing sandplay therapy to Korean-Chinese adolescents from broken families in Yanbian, China, this study sought to give them the opportunity to explore their inner world and thereby help them overcome their psychological difficulties. The study also intended to examine the prevalent images and themes in their sandpictures. Examining themes in sandpictures can provide yet another method to be connected to the sandplay process, which can 
Journal of Symbols \& Sandplay Therapy, Vol.8 No.1.

facilitate a therapist's understanding of a client's process (Turner, 2005).

\section{Research method}

\section{Participants and Procedures}

This study administered sandplay therapy on Korean-Chinese adolescents from broken families in China. Most participants lived in Yanbian, which is designated as an autonomous prefecture for its large number of ethnic Koreans residents. Participants were recruited through written notifications or e-mails sent out to elementary schools and middle schools in the region. Among them, 22 children and adolescents who received guardian consent were chosen for the study. A total of 8 sessions, including a pre-interview, were given individually to the participants for a month in July 2016. The pre-interview included talks with the guardians to obtain information on the participants' personal history. Sandplay was done individually, with one client and one therapist in the therapy room. The therapists were the researchers of this study. The sandplay therapy provided in this study took a Kalffian approach, meaning that the participants engaged in non-directive play in a free and protected space.

In this paper, the sandplay processes of three participants are discussed. These adolescents are from a family that was, at the time of therapy, broken, which means that at least one of the parents were not living with them for different reasons. The basic information of the participants are outlined in Table 1.

Having gained the consent of all guardians and participants prior to therapy, all sessions were voice-recorded, video-taped and photographed for the purpose of analyzing both

Table 1. Basic information of the participants

\begin{tabular}{cccc}
\hline Participants & Gender & Age $($ Grade $)$ & Absence of parent \\
\hline Adolescent A & F & $15(7 \mathrm{th})$ & Mother \\
\hline Adolescent B & F & $15(7 \mathrm{th})$ & Father \\
\hline Adolescent C & M & $15(7 \mathrm{th})$ & Both \\
\hline
\end{tabular}


verbal and nonverbal expressions that took place.

\section{Data Processing}

Before therapy, an interview with the guardians was held to acquire the adolescents' personal information including their history and chief complaints. During therapy, the researchers wrote down noteworthy elements in all sandpictures and also the various verbal and nonverbal expressions made by clients. At the same time, all sessions were videotaped and photographed to observe more accurately the participants' behaviors and the sandpicture contents. Contents that were found to be meaningful after the entire sandplay process were written in notes and, the purpose of which was to develop a focus at the narrow end of the "funnel" (Bogdan \& Biklen, 2006). Sandpictures were interpreted based on the followings: verbal and nonverbal expressions of the participants; different symbols and figures in terms of their representations according to Jungian analytical psychology; and an understanding of the participants' symbolic languages based on their history, chief complaints, dreams and so on (Lee \& Prakash, 2016). This study categorized the themes that appeared in commonly in participants' sandpictures.

Triangulation and peer debriefing were conducted to validate the study. Triangulation refers to a method in which three methods are used in a study in order to check the result. Peer review refers to the process in which the opinions of peer researchers are taken into consideration during data analysis and interpretation ( $\mathrm{Ka}, 2016)$. This study used interview, observation, and photography and documentation for the triangulation method. The results were also revised and supplemented after being checked and supervised by three sandplay therapists.

\section{Sandplay therapy process and analyses}

\section{Analyses of Individual Cases}

\section{1) The case of Adolescent $A$}

Adolescent A was a 15-year-old girl attending middle school at the time. She lived 
Journal of Symbols \& Sandplay Therapy, Vol.8 No.1.

with her mother, who ran her own business, and her twin sister, who was younger of the two. Her parents had met and got married in Korea, and the mother returned to China to give birth to the twins. After the twins were born, the mother left the client with her paternal aunt to be taken care of and left for Japan while leaving the client's twin in the hands of the grandmother. Although the mother returned to China when the client was the age of 4, they did not live together right away. When the client was 6 , the mother lost contact with her husband who went abroad to work and eventually divorced him, and both twins have lived with the mother since then. At first, the client felt awkward and uncertain around the mother. She had never met her father. Sandpictures of adolescent A expressed themes of distance, wounding and hope.

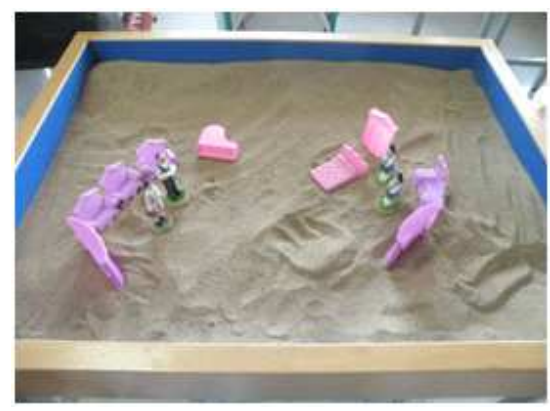

Figure 1. Adolescent A's sandpicture from session 3

Figure 1 is the third sandpicture created by adolescent A. In the left area of the tray are her mother and her grandfather who had come to visit the client's home during the holiday. In the right area of the tray are the client and her twin sister. Although the client described that it is a "holiday," the family members in the house are not mingling at all. This could be a representation of the distance that adolescent A feels with regard to her family members. More specifically, it seems to say that unlike her sister who has always been with her, her busy mother and her grandfather, whom she meets only during the holidays, do not have close relationship with her.

The same topic appeared in her sandpicture from session 6(Figure 2). The family of the president of the town's committee came to visit the mother-in-law. But the mother-in-law is 
busy working by herself, and the family members are looking at a pond while waiting for her.

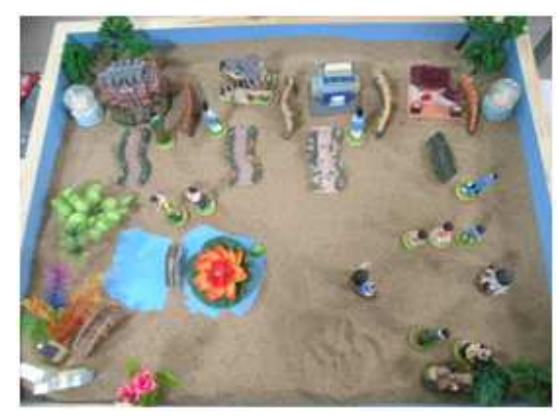

Figure 2. Adolescent A's sandpicture from session 6

Figure 3 is the client's fifth sandpicture. The client first described that the place is an orphanage and later changed it to a daycare center. Children in an orphanage are those who have been separated from their parents for a long time or, in other words, those who were wounded by their parents. As mentioned before, the client first described the scene as an orphanage and then into a daycare center where children are entrusted for a long time. The description of the daycare center coincides with the client's experience of having been separated from the parents during her childhood, and meeting her mother from time to time after her return to China. It is an expression of the wounding that the client had experienced while living away from her parents.

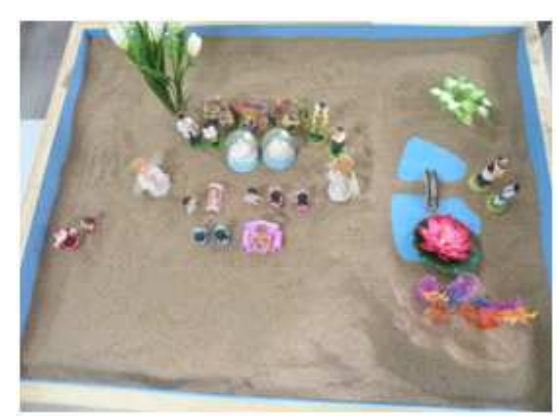

Figure 3. Adolescent A's sandpicture from session 5

"This is the day when the orphanage is being relocated. This person came to entrust 
Journal of Symbols \& Sandplay Therapy, Vol.8 No.1.

her child here, and this person came to find his/her younger sibling $\cdots \cdots$ No. This is $\cdots$ a daycare center where people leave their children temporarily. But you can actually leave the children here for a long time."

Adolescent $\mathrm{A}$, session 5

Figure 4 and Figure 5 are expressions of hope. Figure 4 is client's sandpicture from session 1. In the left rear corner, there is a female figure with a luggage and two airplanes. The client stated her wish to become a person who can travel anywhere on an airplane. Figure 5 was made in session 3. The client placed a bundle of flowers on the left rear corner, which in front of the therapist. Saying that these are artificial flowers, the client explained she has many flowers like these at home as she had heard that they bring wealth to the home.

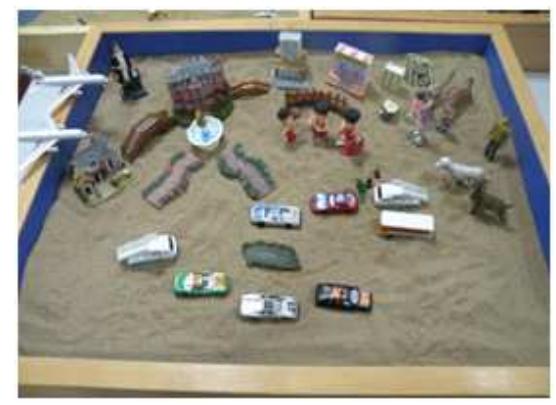

Figure 4. Adolescent A's sandpicture from session 1

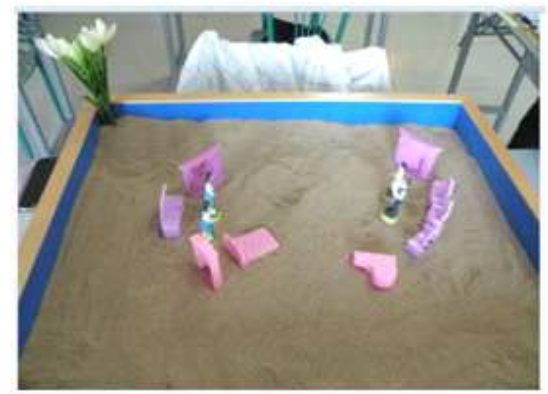

Figure 5. Adolescent A's sandpicture from session 3 


\section{2) The case of adolescent $B$}

Adolescent B is adolescent A's 15-year-old twin sister in middle school. Adolescent B had also began living with the mother at the age of six. She was initially entrusted to her grandmother when she was a baby, and then began living with her aunt and her older twin sister at 11 months old. According to the mother, the aunt favored adolescent A over adolescent B. After being reunited with the mother, adolescent B did not display awkwardness and told the mother that she had been well. But as time passed, unlike adolescent A, adolescent B increasingly began unwilling to talk to the mother. As reported by the mother, she was not as close to the mother as her sister was. Adolescent B's sandpicture showed themes of distance, novelty, and hope.

Figure 6 was created by adolescent B during her second therapy session. It is a display of her memory of her school camping trip. Unlike her optimistic verbal expression that it was a fun place, however, her sandpicture showed loneliness as no human was placed in it. When the therapist asked about the presence of humans, adolescent B said they were all in the house (placed in the left rear corner), sleeping. The dog also has a house (placed towards the front), but it is staring at the humans' house wanting to enter it for food. The statement about the dog hinted that adolescent $\mathrm{B}$ is distanced from her family. This distance was felt from not only her family relationship but also her peer relationship. In Figure 7, her sandpicture created during the fourth therapy session, she created a scene where she is playing ball in the park with her friends. However, rather than everyone playing closely together, they were keeping distance with the ball as if playing separately,

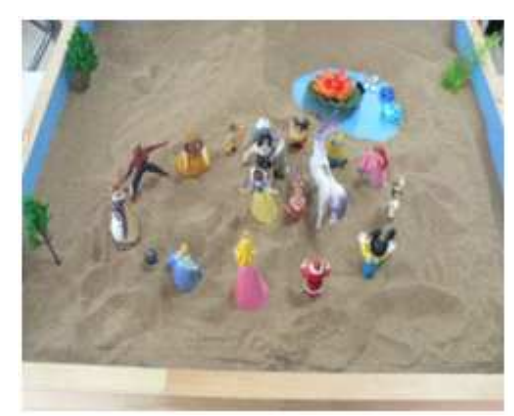

Figure 6. Adolescent B's sandpicture from session 2 
Journal of Symbols \& Sandplay Therapy, Vol.8 No.1.

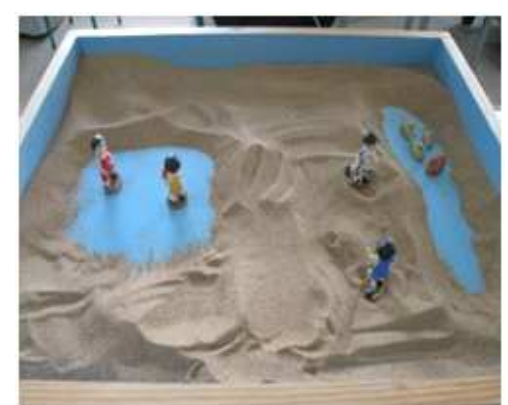

Figure 7. Adolescent B's sandpicture from session 4

An adventure can be said to be a start of a journey. Figure 8 is adolescent B's sandpicture created during her third therapy session. It is a presentation of a ghost cave (or a ghost house). The father, son, and daughter are about to enter the cave. Adolescent B mentioned that the daughter does not want to enter the cave because she is scared, but she is willing to enter because other people are with her. Novelty is accompanied by curiosity, fear, and the resulting challenging spirit. Through fear and curiosity, we try something new, which opens doors to other opportunities. This display represented adolescent B's inner strength that enables her to explore her inner world and find new paths. Figure 9 was created during session 7, and a celebration of new encounters was illustrated.

"They are having a cosplay party. They are celebrating their first encounter and greeting each other."

Adolescent B, session 2

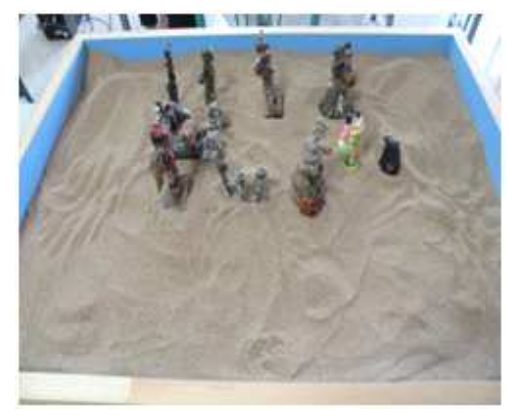

Figure 8. Adolescent B's sandpicture from session 3 


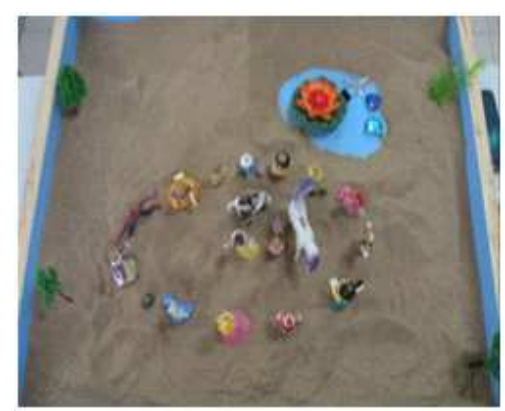

Figure 9. Adolescent B's sandpicture from session 7

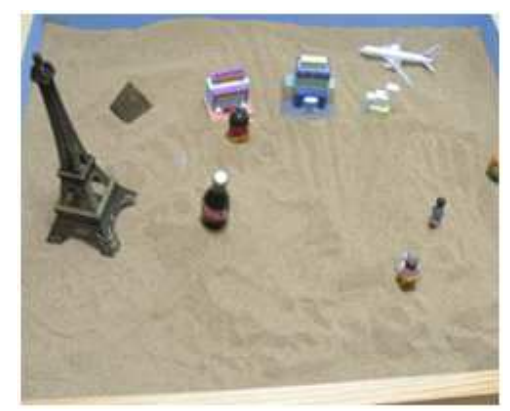

Figure 10. Adolescent B's sandpicture from session 1

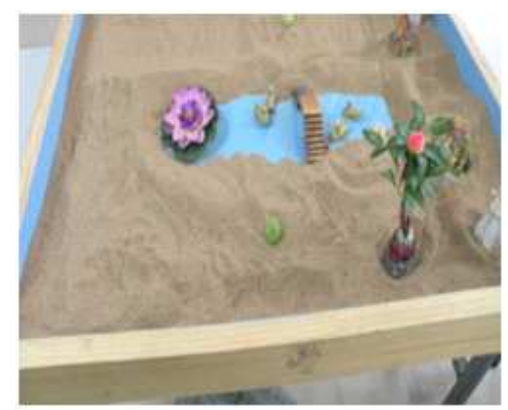

Figure 11. Adolescent B's sandpicture from session 6

Adolescent B expressed hope in her sandpictures from session 1(Figure 10) and session 6 (Figure 11). In Figure 10, she placed the Eiffel Tower, a pyramid, and an airplane that can take her those places, and said that she wanted to see the Eiffel Tower and the pyramids in real life. In Figure 11, she depicted a place she wanted to live with her friend. Her friend's 
Journal of Symbols \& Sandplay Therapy, Vol.8 No.1.

house would be right next to hers, so they could visit each other's houses anytime they want. She expressed her desire to live in a place like this with her friend, without her mother.

\section{3) Case of adolescent $\mathrm{C}$}

Adolescent $\mathrm{C}$ was a male middle school student. $\mathrm{He}$, at the time of therapy, was living with his older sister, grandmother, two older male cousins, and one older female cousin. $\mathrm{He}$ reported that he is close with his sister, the female cousin, and the younger male cousin, but that he is scared of the older male cousin. He frequently argued with his grandmother and did not have a good relationship with his aunt. He had lived apart from his parents since his first birthday, and was very awkward with his mother, whom he meets occasionally. He last saw his father last year, which was a first in a decade. His anger and irritation had grown since 6th grade, to the point that he got irritated and angry at everything. Adolescent C's sandpictures show distance, wounding and hope.

Figure 12 was created by Adolescent $\mathrm{C}$ during his third therapy session. It depicts a farm owned by an elderly couple. He explained that the puppy on the right desires to return to the farm that it left, but could not. It can be said that the distance he felt from his family was represented by the distance between the farm and the puppy. Also, mentioning the house from his first sandpicture from the first session, he expressed how he wanted to approach others, but could not.

"These houses are rich houses. They have everything. But this house is a poor house. People from a poor house cannot go to the rich neighborhood. However, people from the rich neighborhood can go anywhere they want." - Adolescent C, sesson 1.

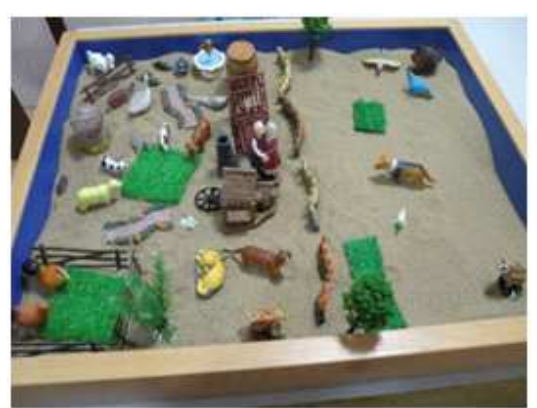

Figure 12. Adolescent C's sandpicture from session 3 
Adolescent $\mathrm{C}$ portrayed his wounded heart through the wounded dog in Figure 13 and the patient in Figure 14, created during session 3 and 6, respectively. The dog was wounded while trying to protect the farm, but nobody tended to it. So the dog was taking a resting while tending to its own wounds. The patient was wounded during his venture to find historical remains and relics. He was taken to the hospital, but he left the hospital to continue his venture. However, he died, failing to find the relics that was right in front of him. These two pictures represented Adolescent C's inner energy to protect himself and to do his best in order to achieve his goals. At the same time, however, they could also represent his wounded heart, and the absence of someone who can heal him or whom he can ask for help.

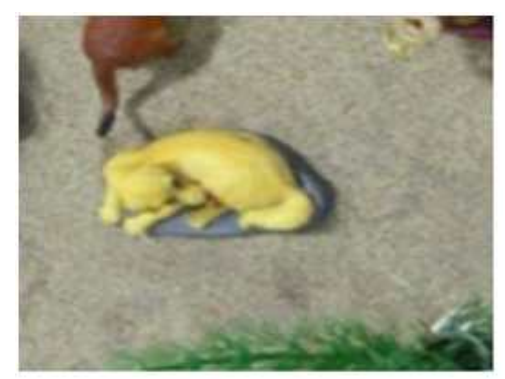

Figure 13. Adolescent C's sandpicture from session 3(close up)

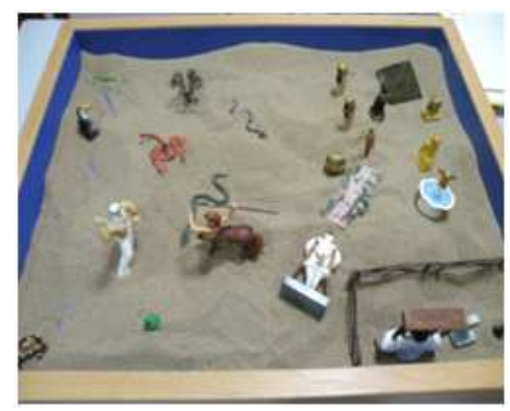

Figure 14. Adolescent C's sandpicture from session 3

Adolescent C's hope was depicted in his sandpicture from session 4 (Figure 15), through the Eiffel Tower. He said that he wanted to see the Tower with his own eyes someday. Also, he expressed that he wanted to live alone in a bigger city, as created in the 
Journal of Symbols \& Sandplay Therapy, Vol.8 No.1.

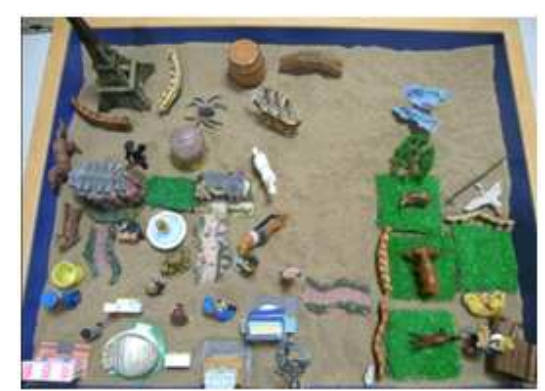

Figure 15. Adolescent C's sandpicture from session 4

sandpicture, than his hometown. Hope signified a new beginning for Adolescent C, and a new beginning meant a break from his family, who cannot care for him.

\section{Analytic Results}

Themes that appeared in the sandplay processes of Korean-Chinese adolescents from broken families can largely be divided into the following four categories:

\section{1) Distance}

The early-in-life experience of separation from parents caused the adolescents to feel distanced from their family. Although they were reunited with their parents in their childhood years, the separation they experienced early in life made it difficult to close the gap in the distance they felt. The intra-family distance cannot be closed by the efforts of the adolescents alone, thus the parents' would have to make active efforts to become closer to them. Because family relationship plays a fundamental role in an adolescent's ability to establish relationships with others in society, feeling distant from the family members will make it difficult for the adolescent to have a stable relationship as he will feel distant from his friends and other social acquaintances. Distance was represented in the sandpictures through physical distance, circumstantial distance, fences, etc. 


\section{Wounding}

Separation from parents and the resulting change in their environment, as well as the eyes of and the discrimination by others have remained as scars for these adolescent. If not treated, such psychological wounds remain and may bring aftereffects during adulthood (Lee, 2016). Through sandplay therapy, adolescents had the opportunity to reflect on their wounds. The theme of wounding was portrayed in the sandpictures through a dog, a patient, and the topic of abandonment.

\section{Hope}

To have hope means there exist something one wishes to achieve. It means that one is aware of what he or she wants, and had the internal motivations to achieve that. Such hope will act as the driving force behind the adolescents' developing not only their external situation, but also their internal self. Engaging in unconscious works through sandplay therapy can help them recognize their unknown desires and urges. The hopes of the participants were illustrated in their sandpictures through airplanes, the Eiffel Tower, and the pyramid.

\section{Novelty}

Novelty may imply an end and a new beginning. The participants of this research were, in terms of psychological development, at the end of childhood and the beginning of adolescence, when relationships with friends and society start become deeper than that with family. Through sandplay therapy, they had the chance to focus on their inner self, discover their new inner aspects, and begin the ego development.

\section{Conclusion}

There was a change in the attitude of the adolescents during the seven sessions of 
Journal of Symbols \& Sandplay Therapy, Vol.8 No.1.

sandplay therapy. At the beginning, they either did not speak a word or spoke quietly, and showed signs of anxiety such as shaking their legs. However, within the free and comfortable environment of the therapy room, they started to talk more about themselves and created sandpictures more actively as each session passed. They stated that the sessions provided them with the opportunity to think about their inner world, and that it was a pity that they did not have the chance to do so before.

he participants of sandplay therapy were Korean-Chinese adolescents from broken homes living in China. Their therapy sessions showed four common themes: distance, wounding, hope, and novelty. This study tried to understand the psychological difficulties the participants went through due to being separated from their parents during the early stages of their lives, and provided them with the opportunity to explore as well as heal their inner world. This study is significant in that it was able to categorize the themes that appeared in their sandpictures, and that it attempted to understand the participants' psychological characteristics through sandplay therapy, a psychotherapeutic approach in which sandplayers express themselves through symbols. The results of this study will be provided as preliminary data that can help enhance the understanding of psychological difficulties faced by Korean-Chinese adolescents from broken families, which stem from the unique environment. Understanding their psychological characteristics and expression methods will be helpful to enhance the psychological health of children and adolescents from broken families. However, the data provided through this study is only from three subjects, making it difficult to generalize the psychological characteristics of all Korean-Chinese adolescents from broken homes living in China. There are more to consider, including the various types of broken homes and relationships with different caregivers. 


\section{References}

Bogdan, R. C., \& Biklen, S. K. (2006). Qualitative research in (validation) and qualitative (inquiry) studies. In It is a method-appropriate education: An introduction to theory and methods. Allyn \&Bacon.

Cho, B., \& Lee, J. (2005). Developmental environment and adjustment of Korean-Chinese children separated from both their parents. Korean Journal of Child Studies, 25(4), 231-245.

Chung, D. (2016). Effects of sandplay therapy on parent-child communication in Chinese-Korean children who experienced separation from their parents. Master's thesis, Namseoul University.

Heo, C. (2002). The psychological, social characteristics of Korean-Chinese youth on Yanbian area in China, and the tasks of counseling. Studies on Korean Youth, 13(2).

Heo, M. (2014). Sandplay therapy case study: A child with emotional regulation problem caused by attachment trauma. Journal of Symbols \& Sandplay Therapy, 5(2), 57-76.

Hwang, Y. (2013). Who are the "Jonseonjok"? - Definition and overview. Journal of Korea-China Future Research Center, 1, 11-128.

Jang, M. (2017). Analytical psychology and sandplay therapy. Seoul: Hakjisa.

Ka, S. (2016). Understanding the educational meaning of the living world of "Distinguished children" in a rural village in China. Booklet for 2016 Autumn Academic Conference of The Korean Society for the Study of Anthropology of Education.

Kim, G. (2012). Effect of structured group sandplay therapy for children's self-perception and ego-resilience. Master's thesis, Myongji University.

Lee, S., \& Prakash, S. (2016). Image experiences in sandplay therapy in adolescents living in welfare facilities who suffered Nepal earthquake. Journal of Symbols \& Sandplay Therapy, 71), $81-96$.

Lim, S. (2013). The effect of happiness boosting programs on the level of happiness and school life adaptation of children from broken families in Yanbian, China. Master's thesis, Jeju National University.

Ri, H. (2014). Cultural continuity and transformation of Josenjok(Korean-Chinese) families by examining raising children practices. Joongang Siron, 39, 77-109. 
Journal of Symbols \& Sandplay Therapy, Vol.8 No.1.

Turner, B. A. (2009). The handbook of sandplay therapy. Seoul: Hakjisa. 